pact. The only paper in the fourth section describes the difficulties involved in palaeodemographic reconstruction and provides a good overview of what we would like to know but usually find hard to document archaeologically.

As the editors undoubtedly expected, this book is more valuable in what it shows up rather than what it shows off. The contributors have demonstrated that we know very little of the climatic and environmental circumstances that preceded the appearance of domesticates, that the preservation of reasonable samples of plants and animal bones in archaeological contexts is variable but generally poor, that we have very inadequate dating of critical changes, and that models for understanding how and why people shift into agriculture or pastoralism are only now emerging. More seriously we see an archaeological record that is so residual and fragmentary that it becomes malleable and an easy victim for a predatory hypothesis. In these circumstances it is extremely tempting to "fit" the archaeological evidence

\section{Angles on aphids}

linguistic histories, climatic reconstructions or, more commonly, ethnographic models.

Several of the contributors (particularly but not only Stahl, Ambrose, Klein, Gifford-Gonzalez, and McIntosh and McIntosh) make the point that archaeological observations have to generate some internal and independent consistency. This comes only from sustained multidisciplinary research into regional sequences of events, something that few parts of Africa have so far enjoyed. What is known is largely in this book. Although I would liked to have read more discussion of theory and method, to have seen more concern with social than ecological issues and to have heard more talk of process, I recognize and recommend here a valuable summary of our current understanding of "the causes and consequences of food production in Africa".

John Parkington is in the Department of Archaeology at the University of Cape Town.

this an outstanding rapid-reference volume.

Search for hay in a needlestack

\section{Harry Hertz}

\section{Organic Trace Analysis.}

By K. Beyermann.

Ellis Horwood/Halsted: 1984. Pp.365. f35, \$74.95.

THE search for trace organic substances in complex inorganic and organic matrices is one of the most challenging problems facing chemists. It pervades all aspects of our lives: the water we drink, the food we eat, the environment in which we work and live, the quality of our manufactured goods and many aspects of our day-to-day health. Klaus Beyermann's Organic Trace Analysis, a generally very readable translation of the original German edition, is the first comprehensive description of this developing field of analytical chemistry.

Beyermann has aimed the treatise at a diverse audience, from the professional analyst to "science administrators, biologists, politicians [and] forensic experts". While this is an admirable goal, it has led to occasional identity crises and uneven presentation of various topics. Nevertheless, if readers are willing to pick and choose what to read they will find that the book does present an effective overview of the field.

An outstanding feature is the references, some 3,000 of them. Much of the information on previous studies is reported in tables, permitting easy access to the literature. Furthermore, all the tabular entries (as well as the text itself) are extremely well indexed in the back of the book, making
The order of presentation follows the logical sequence of analysis: from general aspects through sampling, sample handling, component separations and detection.

There are, however, some flaws. The book as a whole is less evaluative of the literature than one would like, the author usually choosing to cite relevant works without any commentary. Section 2.4, which deals mainly with statistics, was not contributed by Beyermann and is not as well written as the rest of the book. The level of detail in this introductory section is perhaps excessive, while the references here are more parochial than they are elsewhere; this could dissuade some readers from continuing. And the topic of sampling and storage is treated in a manner which belies the problem in this area of assuring analyses which accurately represent the native (in situ) concentration of the species of interest.

As with any rapidly evolving field, by the time a book has been through the publication mill new discoveries have appeared and contributed to the science being discussed. Here consideration of such techniques as fast atom bombardment in mass spectrometry and the impact of monoclonal antibodies on immunoassay is not included, and thus the book already has a somewhat dated look in parts. For all that, the publication of Organic Trace Analysis is undoubtedly a milestone in analytical chemistry. It is a handy reference volume for the practising analyst and a valuable introduction for the generalist who is prepared selectively to read sections of the book.

Harry Hertz is Director of the Center for Analytical Chemistry at the US National Bureau of Standards, Gaithersburg, Maryland. (1985 Nature Publishing Group

\section{Llewellyn}

\section{Aphid Ecology.}

By A.F.G. Dixon.

Blackie/Methuen: 1985. Pp.157.

f17.95, \$39.95.

APHIDS are specialist phloem-feeding insects that have received world-wide attention, both because of their importance as agricultural pests and because of the intricacy and diversity of their biology. A book on aphid ecology by a leading research worker in both fields will thus attract attention from a number of angles. Satisfying all potential readers - especially in a mere 136 pages of text - is a tall order, but Professor Dixon has succeeded remarkably well.

This book is as much about the biochemistry, physiology, genetics and evolution of aphids as about patterns and processes of ecology; it contains not only information about a specialist taxon of insects but constitutes an integrated approach to ecology which, although often talked about, is rarely attempted. Many areas are excellently reviewed. The accounts of such topics as "galling", polymorphism, genetic change, sexual morph production and hostalternation are a delight, and a large literature on the population dynamics of several species has been crystallized into a fascinating and informative chapter. A few subjects do not catch the imagination, however; the section on host plant finding and nutrition, for example, is not particularly convincing. The book is peppered with the author's own ideas and theories - on aphid size, ovariole number, reproductive strategies and the aphid fauna of the tropics - which may not find universal approval but which will stimulate the work of aphid biologists for some time to come.

There are well over 100 graphical figures, as befits an experimental, quantitative approach to ecology, but I often found them of little value because of the lack of adequate background information. The condensed treatment of some topics, in particular reproductive strategies and aspects of migration, may baffle the general reader, and it is a pity that the space taken by some figures was not used to extend consideration of difficult concepts such as these.

After reading this book few will disagree that a broad approach to ecology, drawing upon diverse areas of biology, is anything other than desirable. Here it has resulted in a challenging text which surely heralds the demise of the specialist and blinkered approach to ecology so prevalent over the past 30 years. of London. 